\title{
El sistema financiero en Colombia: una historia por contar
}

Ocampo, J. (2015). Una historia del sistema financiero colombiano. Bogotá: Asobancaria/ Portafolio.

\section{Ana María Leguizamón ${ }^{1}$}

\section{Astrid Viviana Romero}

Para citar: Leguizamón, A., y Romero, A. (2018). El sistema financiero en Colombia: una historia por contar. Ciudad Paz-ando, 11(2), 100-103. doi: https://doi.org/10.14483/2422278X.14275

Fecha de recepción: 02 de noviembre de 2018

Fecha de aprobación: 03 de diciembre de 2018

El protagonismo de la Asociación Bancaria de Colombia en la promoción, la contribución al conocimiento y diseño de la política monetaria y financiera nacional habla por sí sola de la creciente influencia de la banca privada en el país y de la profundización financiera que este sector ha facilitado. El proyecto conjunto liderado por el diario Portafolio, líder en información de economía y negocios y La asociación gremial financiera colombiana (Asobancaria) de esquematizar y registrar minuciosamente la historia del sistema financiero, se articula con la academia para desarrollar un insumo para la investigación y el estudio de las políticas públicas que han caracterizado la estructura económica del país.

El economista José Antonio Ocampo a quien fue encomendada la tarea, fue nombrado en febrero de este año Codirector de la junta Directiva del Banco de la República, actualmente se desempeña como profesor de la Universidad de Columbia, es Director de la Misión para la Transformación del Campo en Colombia y Presidente del Comité de Políticas de Desarrollo del Consejo Económico y Social de las Naciones Unidas; organización internacional donde en años previos ha desempeñado cargos como secretario ejecutivo de la Comisión Económica para América Latina y el Caribe (CEPAL), y secretario general adjunto para Asuntos Económicos y Sociales. Durante el libro el autor se sirve de dos estructuras complementarias y transversales para analizar la historia del sistema financiero colombiano, dividido en cuatro momentos coyunturales contenidos en el periodo 1951-2014. La revisión de cada uno de los periodos se realiza desde una perspectiva macroeconómica donde se tienen en cuenta elementos como el comportamiento de la economía nacional en función de indicadores agregados como el valor total de los bienes y servicios finales producidos por un país durante un tiempo definido, la tasa de desempleo, los índices de precios; todo ello con el fin de entender cómo funciona y cómo se comporta la economía nacional en su conjunto.

Ocampo inicia la historia del Sistema Financiero en el año 1951 y culmina su análisis en 2014; un periodo de 63 años que pese a lo extenso de su delimitación

1 Integrante del Semillero In-Vestigium, Estudiante del programa de Negocios y Relaciones Internacionales, Universidad de La Salle. Correo electrónico: aleguizamon19@unisalle.edu.co

2 Integrante del Semillero In-Vestigium. Estudiante del programa de Negocios y Relaciones Internacionales, Universidad de La Salle. Correo electrónico: aromero03@unisalle.edu.co 
temporal, logra captar importantes acontecimientos que construyeron la historia del sector desde antes de 1951 ,influenciados por la transición del modelo de intermediarios financieros-impulsados por la Misión Kemmerer en 1923- hacia la consolidación en los años noventa de la Multibanca privada, la cual gira en torno a conglomerados financieros que han logrado influir y robustecer la privatización del sistema.

Así pues, el contenido del libro es una historia bien contada, dinámica y comprensible del sistema financiero, narrada desde la academia, pero impulsada por la iniciativa del gremio financiero colombiano Asobancaria y por uno de los medios de comunicación del país más influyente en materia económica. Esta interesante alianza da cuenta del interés de documentar fidedignamente la evolución de un sector que, si bien ha excluido muchas veces al sector público en su configuración, está en deuda con el sector privado, el cual juega un rol fundamental una vez iniciado el periodo de la banca libre en Colombia, pues fue allí donde en un primer momento se materializó la iniciativa de establecer bancos que cumplieran con la función, de giro, descuento y depósito y que además tuviera la facultad de emitir billetes . Los bancos comerciales e incluso las casas comerciales privadas fueron pioneras ejerciendo estas funciones en el país cobijadas por la ley colombiana que avalaba la libre emisión de billetes y metálico, sin embargo la laxitud del Estado colombiano en materia bancaria obedeció a la indecisión y trabas burocráticas en el establecimiento de un banco central, que para el país representó casi una tarea imposible al menos durante todo el siglo XIX.

Esta recopilación recoge nombres de personajes, entidades, instituciones privadas y públicas, grupos y conglomerados; todos aquellos que construyeron y hoy conforman el poderío que representa el sistema financiero en Colombia. En dicho compendio el autor se abstiene de exponer una postura frente al papel de la institución que acompaña el proyecto, razón por la cual durante los capítulos el análisis no seguirá de cerca la influencia de Asobancaria en la configuración del sector financiero, en cambio resaltará los acontecimientos más importantes de éste, presentando su transformación y evolución.

En cada uno de los capítulos que a continuación se reseñaran, Ocampo desarrolla una descripción del entorno macroeconómico nacional e internacional de cada periodo analizado. Una vez sitúa al lector en un contexto, se introduce de lleno en explicar el marco institucional, regulatorio y la evolución del sistema financiero en cada una de las etapas de la historia económica y financiera del país, respaldado por una concisa sustentación empírica contenida en gráficos, cuadros y trabajos de investigación que proveen descripciones, análisis y apreciaciones pertinentes.

La minuciosa revisión histórica realizada por el autor le permite afirmar hechos como el dinamismo positivo de la economía del país ligado a exportaciones cafeteras y a la expansión de nuevas instituciones privadas durante 1974, cuando se da por terminado el periodo de la fuerte represión financiera. Las repercusiones directas de este y muchos otros momentos son observables en los distintos gráficos que el autor construye con respecto a la profundización financiera, incluyendo una caracterización de las entidades financieras de la época y la creación las corporaciones de ahorro y vivienda.

En la introducción del libro el autor hace otra importante afirmación de lo que es y representa realmente la función de los agentes crediticios y protagonistas del sistema financiero; puntualmente éstos son los intermediarios y facilitadores de múltiples transacciones comerciales que se llevan a cabo con una cierta cantidad de liquidez que tiene en su poder. Pese a no profundizar la anterior afirmación, para el autor es importante aclarar que el fin de este sistema es la optimización máxima de ese dinero, con el cual las instituciones ejercen como intermediarias y ofrecen financiamiento al sector privado y público. Es en este punto donde Ocampo considera necesario precisar y establecer cuál debe ser la función del sector privado dentro del sistema financiero colombiano, manifestando que debe ser un agente optimizador y un ágil administrador de dineros públicos y privados, mientras el papel del gobierno se limita a la perfecta regulación y supervisión; más no administra dicha liquidez.

Una vez realizada la caracterización de la intermediación financiera, el autor ahonda en la relación de los ciclos económicos con los 'booms' de financiamiento externo y las crisis financieras internas- que a su vez considera constantes históricas-, con el mercado nacional y el financiamiento internacional. A lo largo del texto y a través de las distintas etapas en las cuales se estructura esta historia, son explicadas de manera transversal las que hasta ahora siguen siendo las principales problemáticas del sector financiero; en primer lugar, la asimetría de información a la que se enfrentan los distintos agentes involucrados implicando un riesgo latente en una transacción financiera, $\mathrm{y}$, en segundo lugar, la dependencia del sector al financiamiento externo.

A lo largo del libro es posible identificar una interrelación entre 'constantes' que se repiten en cada una de las etapas; el primero de ellos es la profundización financiera y su correlación positiva con el crecimiento económico, donde a mayor disponibilidad de crédito, mayor realización de actividades comerciales y productivas. A su vez relacionado con la naturaleza del comportamiento financiero que involucra operaciones a futuro; la segunda constante será el inherente riesgo que caracteriza al sector y que se traduce en una fuerte presencia de ciclos económicos influenciados siempre por dinámicas macroeconómicas extranjeras; el tercer elemento será la creciente participación del sector privado; y por último, el criterio de las normas regulatorias en cada etapa. Por 
consiguiente, tanto la profundización financiera como el riesgo característico del sector se evidenciarán en las cuatro etapas reseñadas brevemente a continuación.

La era de fuerte intervención estatal en el sector financiero (1951-1974); la represión financiera aludida por el autor no se debe a otra cosa que a las administraciones poco fructíferas que ejerció el gobierno sobre muchas instituciones durante el periodo de 1951-1974, a partir de la década de los cincuenta, y en particular, con la reforma de 1951 que adoptó un esquema severamente estructurado de intervención en el manejo crediticio. No obstante, lo que el autor distingue para dar paso a una evolución del sector, es la política de fomento, la cual se origina mediante la consolidación de la banca especializada y la represión de la privada.

En el segundo periodo es Auge, crisis y búsqueda inconclusa de un nuevo modelo de desarrollo financiero (19741990); Ocampo abarca la transición entre el periodo de la banca especializada y represora hacia la de mayor libertad auspiciada por la apertura económica; dicha apertura en cuanto elemento estructural del análisis económico siempre debe ser citada pese a ser en la mayoría de los casos objeto de controversia. En materia financiera las reformas de liberalización económica fueron sustanciales; pues obedecieron también en su momento a la cambiante coyuntura macroeconómica, que, así como presenció una bonanza en la segunda mitad de los años setenta, también debió enfrentarse a una crisis en la primera mitad de la década de los ochenta. Según el autor durante este periodo la profundización financiera no avanzó de forma significativa, mientras la concentración del sistema y la oficialización de la banca fueron además de la crisis los otros defectos congénitos a la evolución del sistema financiero durante esta época.

El periodo que cubre el capítulo La liberalización y el gran ciclo de auge y colapso financiero (1990-2003); tiene por protagonistas la apertura económica, la constitución de 1991 -la cual entrega la autonomía del Banco de la Republica-, y el sistema crediticio colombiano que ahora accedía a capitales externos. Al finalizar este periodo se vivió una crisis significativa para el sector; una vez apaciguada esta crisis, el fenómeno de la privatización tomó mucha más fuerza apoyado en gran medida por la conformación de conglomerados financieros. De ahí que, la euforia sin precedentes que la liberalización representó se vio reflejada en los niveles de profundización financiera, en los rendimientos y en la calidad de los créditos otorgados; sin embargo, la aceleración del proceso de privatización no fue suficiente para perturbar la permanencia de los bancos de desarrollo, los cuales con los nuevos cambios estructurales fueron organizados de forma independiente al banco emisor.

La gran expansión de la banca privada (2004-2014); fue la etapa donde avanzó aún más el proceso de profundización financiera, impulsada por la banca privada que generaba una fuerte concentración en el sector. Los avances en materia regulatoria permitieron al país encontrar una estabilidad financiera que los hacia más resistentes a crisis internacionales como la vivida en el 2008-2009. Otros desarrollos importantes como el crecimiento de grupos financieros no sólo en el país sino también en América Latina, nuevos mecanismos de inclusión financiera, el crecimiento de fondos de pensiones e inversión, la diversificación del mercado bursátil; todos estos avances constituyeron la fase más exitosa de la banca privada colombiana hasta ahora.

La cronología como herramienta utilizada por el autor para explicar los cuatro momentos hace evidente en cada uno de ellos el cambio de dirección de la intermediación financiera, la cual pasa de manos estatales a grandes entidades privadas iniciada la década de los ochenta. Para el autor es importante resaltar que el éxito financiero de los privados no se tradujo necesariamente en un bienestar macroeconómico nacional o en una banca especializada funcionando óptimamente, pues la concentración del sector financiero en manos de pocos representa una alerta vigente para el gobierno interventor, ya que los márgenes de intermediación siguen siendo muy altos en Colombia; los retos en materia de regulación deben orientarse hacia esta dirección pues si bien, con la apertura económica la cartera colombiana pasó a manos de privados, estos no tienen libre accionar sobre ella, y en cambio deben estar sujetos a una serie de regulaciones que eviten cifras cada vez más escandalosas en los altos índices de concentración de riqueza.

El trabajo de Ocampo a lo largo de los capítulos cita los grandes retos del sistema financiero concernientes a la presencia creciente de los conglomerados nacionales en el exterior. De igual forma expresa preocupación por las nuevas coyunturas que atraviesa el país donde el creciente endeudamiento externo aún prevalece, la tasa representativa del mercado (TRM) sigue incrementándose debido a la devaluación del peso colombiano frente al dólar y donde la inflación que en el año 2016 superó por mucho el margen de Inflación Objetivo establecido por el Banco de la República.

El debate que propone el autor en torno a políticas económicas futuras busca ser la respuesta del lector ante una lectura sencilla y masiva que da cuenta de la construcción del sector financiero en Colombia y su funcionamiento. Un texto académico con dichas cualidades dotará de la facultad a otro tipo de público para entender y debatir sobre el diseño de políticas de un sector que compromete directamente el crecimiento económico de todo un país.

No obstante, las consideraciones resultado del análisis en el último periodo de tiempo pese a estar sujetas a la rigurosidad histórica del autor, olvidan elementos coyunturales de las últimas dos décadas, lo cual crea sesgos en el análisis; elementos ausentes como el narcotráfico, la fallida seguridad nacional y la falta de gobernabilidad 
característica de las administraciones en la década de los noventa, son elementos que en el último periodo de tiempo no son tomados en cuenta.

La coyuntura extendida suscitada por los numerosos procesos de negociación con las FARC y que datan desde antes de la administración Pastrana, no fue tenida en cuenta para el análisis económico y social del libro. En particular durante la administración de la última década de los noventa hicieron evidente la ausencia de gobernabilidad en el país, provocando consecuencias en el sector económico y financiero colombiano. Así como no fue tomado en cuenta el fracaso de estas negociaciones, tampoco tuvo importancia añadir el escándalo por el proceso 8000 que salpicó la administración de Ernesto Samper en el análisis, o el auge y expansión del narcotráfico colombiano que alcanzó su punto álgido en la década de los ochenta y que de alguna forma modificó las dinámicas del incipiente sistema financiero del país.

Otros elementos que pudieron tener tópico de mayor análisis y comprensión en el periodo 2004-2014 es el análisis macroeconómico concerniente a la dependencia de la economía colombiana ante los precios del petróleo, elemento que sin lugar a duda revertió tendencias en el año 2012. De forma simultánea el inicio de los diálogos de Paz en La Habana y el posterior proceso de paz significaron cambios sustanciales en las finanzas nacionales durante la aún vigente administración Santos Calderón, donde una parte importante del presupuesto nacional consignado en el Plan Nacional de Desarrollo 2018 fue y es actualmente destinado para la correcta implementación de los Acuerdos de Paz que finalmente el Estado colombiano logró pactar con las FARC. Así pues durante la administración Santos un ratio importante de gasto nacional estuvo fuertemente relacionado con la negociación y posterior implementación de los acuerdos, razón por la cual tener en cuenta esta variable en el análisis permite esbozar una perspectiva mucho más objetiva y menos sesgada del panorama macroeconómico del país particularmente en la administración 2010-2014 /2014-1018.
La reflexión final del autor, deja una puerta abierta a un debate donde el cuestionamiento gira en torno al nuevo panorama que empieza a dibujarse en materia macroeconómica para Colombia; en donde el sistema financiero y la banca privada tienen el desafío de proveer herramientas a la economía nacional para superar futuros vaivenes, nunca exentos de las fluctuaciones de los ciclos económicos y las dinámicas macroeconómicas internacionales. Por ello es necesario cuestionarse acerca de las posibles decisiones del sector, frente a la dinámica actual del país, el cual se recupera en un contexto macroeconómico de una nueva reforma tributaria, estancamiento y caída de la inversión.

Por lo anterior, pese a culminar el análisis en el 2014, los cuestionamientos respecto a la profundización impulsada por la Multibanca privada, la necesidad de una acertada regulación y supervisión financiera son temas que deben continuar siendo predominantes en la agenda del sector financiero colombiano, la cual también evoluciona junto a diferentes escándalos financieros como lo son Interbolsa, Estraval y distintas Pirámides con los cuales se puso a prueba la eficiencia de las múltiples instituciones de supervisión y regulación del país.

Cuestionamientos y una posición crítica se dibujan en un escenario posibilitado por iniciativas académicas como la auspiciada por Asobancaria con la recopilación de la historia del sector financiero. Proyectos de este calibre proponen un espacio inclusivo donde tanto público especializado puede participar y uno no especializado igualmente participa, se involucra y sobre todo se entera de la realidad financiera y del sistema que rige este sector en el país.

La iniciativa académica propende hacer del acceso la información un proceso mucho más fácil y amable para todo aquel que se interese a través de material como el que provee Asobancaria que tiene como fin último- y como ellos afirman en el prólogo del presente libro reseñado- debatir y discutir las distintas temáticas que transforman y han conformado la construcción del Sector Financiero Colombiano.

\section{(C) $(\Theta \odot$}

